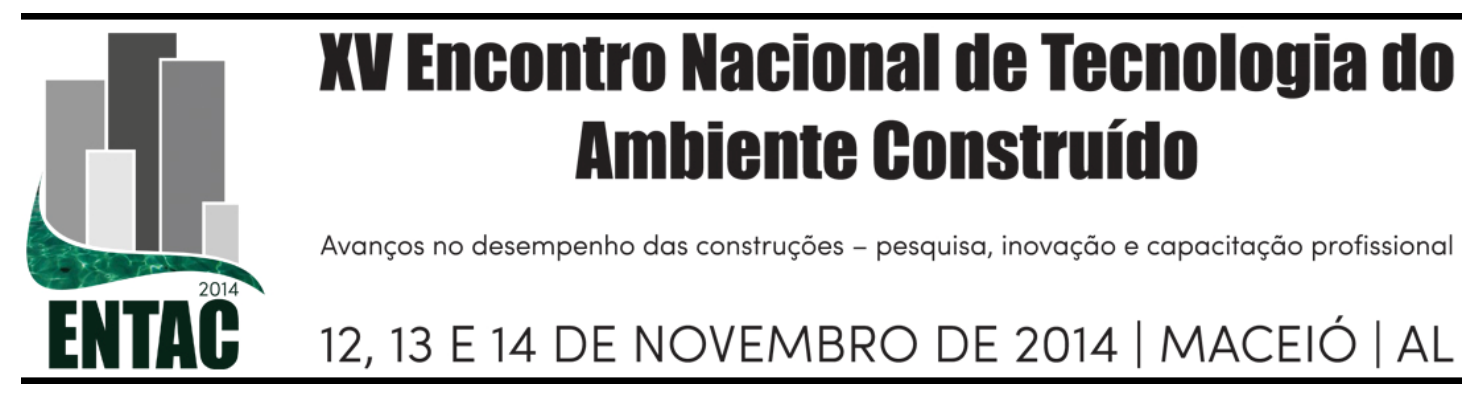

\title{
ANÁLISE DO PROCESSO DE PROJETO EM OBRAS DE READEQUAÇÃO PREDIAL EM INSTITUIÇÃO UNIVERSITÁRIA PÚBLICA
}

\author{
MARTINS, Rute Maria de Paula (1); ANDERY, Paulo Roberto Pereira (2); \\ STARLING, Cícero Murta Diniz (3) \\ (1) UFMG, e-mail: rute@dpfo.ufmg.br, (2)UFMG, e-mail: pandery@ufmg.br, (3) UFMG, e-mail: \\ cicerostarling@ufmg.br
}

\begin{abstract}
RESUMO
O presente trabalho tem o objetivo de elaborar uma análise exploratória do processo de projeto em obras de readequação predial em instituição universitária pública. O método empregado é o de estudos de caso múltiplos, sendo um deles apresentado no trabalho. Inicialmente apresenta-se o referencial teórico como marco conceitual da pesquisa. A partir de procedimentos metodológicos descritos no trabalho, através de estudos de caso com base em fontes de evidências como análise documental, observação direta de rotinas de trabalho, entrevistas e visitas a obras, é caracterizada a estrutura funcional da Instituição e a sua relação com o processo de projeto, bem como os workflows do processo de projeto que caracterizaram os empreendimentos estudados. Um dos três empreendimentos estudados é caracterizado, apresentado o fluxo de informações ao longo do processo de projeto e os aspectos relevantes do mesmo, como programação, detalhamento das fases, mecanismos de acompanhamento e coordenação. Os principais problemas dos projetos são identificados a partir da visita às obras e análise documental, sendo que uma análise desses problemas é feita à luz do processo de projeto. Diretrizes para a melhoria do processo de projeto são brevemente delineadas, levando-se em consideração as particularidades dos projetos em instituições universitárias públicas.
\end{abstract}

Palavras-chave: Processo de projeto, Instituições universitárias públicas, Gestão de projetos.

\begin{abstract}
The present paper aims to develop an exploratory analysis of the design process for building retrofitting construction in public university institution. The method employed is the multiple case studies, one of them presented here. Firstly, it is presented a theoretical background for the study. From methodological procedures described in the study, through case studies from sources of evidence such as document analysis, direct observation of work routines, interviews and visits to constructions, the functional structure of the Institution and its relation to the design process is characterizes, as well as the workflows of the design process that characterizes the cases studied. One of the three designs studied is characterized, presented the flow of information throughout the design process, and relevant aspects of it, such as programming, detailing the phases, monitoring and coordination. The main problems of the projects are identified from the visit to the constructions and documentary analysis, and an analysis of these problems is made in light of the design process. Guidelines for the improvement of the design process are briefly outlined, taking into account the particularities of the designs in public university institutions.
\end{abstract}

Keywords: Design process, Public university institutions, Design management.

\section{INTRODUÇÃO}

O presente trabalho apresenta resultados de projeto de pesquisa já concluído, no qual se procurou estudar o processo de projeto em obras de readequação predial em Instituição 
universitária pública. Como etapa preliminar, é caracterizado o processo de projeto da Instituição universitária pública investigada. Em um segundo momento, apresentam-se resumidamente as características de obras específicas de readequação predial. Na sequência, são feitas comparações com outras Instituições universitárias públicas e por fim, esboçadas algumas diretrizes para a melhoria do processo de projeto em questão.

No caso específico de instituições universitárias públicas, a gestão do processo de projeto tem algumas particularidades, ainda que possam ser aplicados procedimentos de gestão do processo de projeto mais gerais, como os indicados na literatura recente, por exemplo, TZORTZOPOLOUS e COOPER (2007), ANDERY, CAMPOS e ARANTES, (2012) e KAGIOGLOU et al. (2007). Para essas Instituições, diversos trabalhos apontam para a especificidade da gestão do processo de projeto, por exemplo, MOTA e SALGADO (2013).

Entre os trabalhos recentes, ESTEVES (2012) destaca aspectos como a forte intervenção dos promotores e usuários na definição das soluções de projeto e na própria gestão do processo; a dificuldade de se implementar modelos de gestão do processo de projeto, em função da descontinuidade das políticas internas; o condicionamento das decisões à dinâmica de obtenção de verbas; a segmentação do processo de projeto, em função das imposições da Lei 8.666/1993 (BRASIL, 1993); e a falta de critérios claros e planos diretores para nortearem as soluções de projeto.

A necessidade de reformulação de espaços físicos em edificações existentes é muito dinâmica em Instituições universitárias públicas, quer seja pela necessidade de adaptação dos mesmos a novos usos, quanto pelo atendimento às exigências de acessibilidade, sustentabilidade e estética, ampliação, modernização de instalações face às novas tecnologias, além de restauração para preservação do patrimônio público. Desta feita, são executadas diversas obras e reformas que apresentam muitos problemas de gerenciamento, controle dos processos e de execução.

Nesse contexto, o presente trabalho faz um diagnóstico sobre o processo de projeto na Instituição universitária pública pesquisada.

\section{MÉTODO}

Utilizou-se o método de estudos de caso múltiplos, sendo um deles apresentado no presente trabalho. Detalhes do procedimento metodológico são omitidos por brevidade, sendo apresentados por MARTINS (2014). A pesquisa foi realizada em uma Instituição universitária pública, e compreendeu as seguintes fases: a) pesquisa bibliográfica; b) planejamento do estudo de caso; c) seleção dos casos; d) escolha de caso piloto para validação da metodologia; e) caracterização dos empreendimentos estudados e f) pesquisa de campo com a coleta dos dados. Realizaram-se análise de documentos, entrevistas, acompanhamento de rotinas de trabalho a partir de roteiros estruturados, além de visitas e acompanhamentos das obras, com registro documental e fotográfico.

\section{CARACTERIZAÇÃO DA INSTITUIÇÃO E DO PROCESSO DE PROJETO}

A estrutura administrativa que engloba as atividades de gestão das edificações da Universidade em questão passou recentemente por vários processos de reestruturação. $\mathrm{O}$ processo de desenvolvimento de projetos da Instituição tem sofrido modificações ao longo dos anos, por motivos diversos, destacando-se as alterações na legislação pertinente ocorridas recentemente. A Lei 12.349/2010 (BRASIL, 2010) tornou-se um marco regulamentar na maneira de se projetar no escritório público pesquisado. 
A Instituição, que por muitos anos realizou obras por administração direta, através de sua Fundação de Apoio, se deparou com a necessidade de aprimorar seus projetos elaborados com vistas à contratação dos serviços. Diante desse contexto, o escritório de projeto pesquisado passa por uma fase de adaptação e aprimoramento de suas atividades projetuais, em atendimento às exigências legais quanto à elaboração do projeto básico necessário à licitação dos serviços (IBRAOP, 2006).

O fluxograma a seguir (Figura 1) ilustra, de maneira simplificada, o sequenciamento macro do processo de projeto à época na Instituição pesquisada e adotado no estudo de caso ora apresentado.

\section{Figura 1 - Fluxograma com sequenciamento macro do processo de projeto estudado}

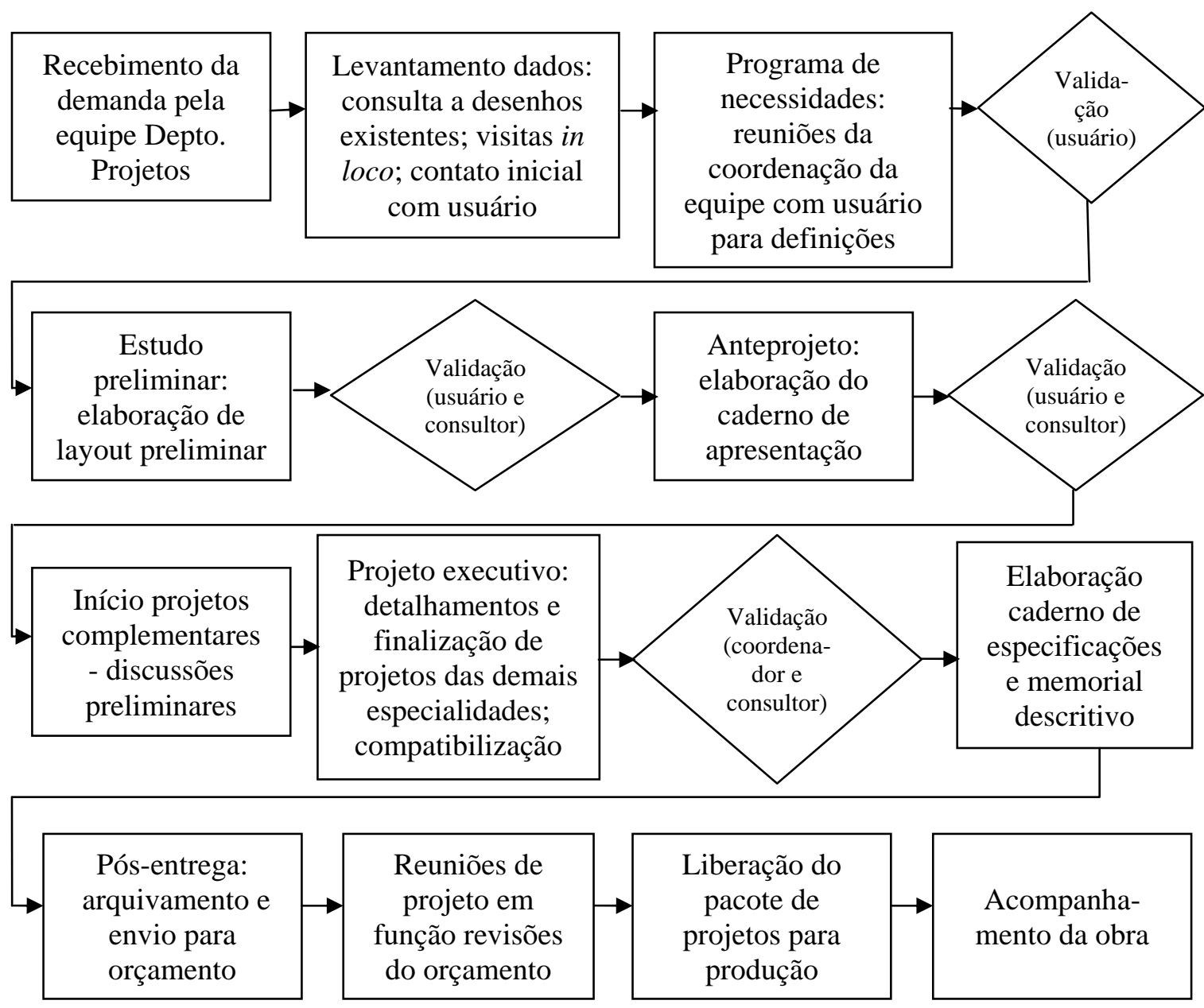

Fonte: Autores

Na maioria dos casos, a autoria do projeto de arquitetura é do arquiteto da Instituição, salvo os casos em que são adquiridos no mercado devido à complexidade ou indisponibilidade de equipe para desenvolvê-lo em tempo hábil, em função de prazos pré-estabelecidos. Quanto às demais especialidades, podem ser necessárias contratações, com a supervisão e validação da solução por parte de técnico da própria Instituição. Internamente são desenvolvidos pequenos projetos complementares relativos a instalações prediais.

Embora a coordenação seja exercida por arquiteto da Instituição, no caso da contratação de projetos, são levantadas dificuldades quanto à cobrança de prazos e tarefas previstas 
no planejamento do projeto. Ademais, quando os projetos complementares são contratados de empresas distintas, podem ocorrer dificuldades na compatibilização e coordenação dos mesmos devido à superposição de supervisão.

No processo de projeto são envolvidos os projetistas da Instituição (vinculados à equipe escalada para desenvolvimento da solução), consultoria de projetos (se necessário), o arquiteto coordenador da equipe e os técnicos de engenharia quando solicitados, muitas vezes vinculados à manutenção. Outros setores também podem ser envolvidos, como os de licitações, contratos, documentação, entre outros.

O projeto em questão foi desenvolvido por etapas e áreas específicas. Foram previstas pelo menos três etapas de intervenção, para que não houvesse prejuízo das atividades administrativas desenvolvidas, facilitando, assim, a disponibilização de recursos para atendimento à demanda. Trata-se de readequação no prédio do Departamento de Recursos Humanos, voltado à gestão de pessoas, responsável pela posse de servidores e treinamentos, sendo inviável qualquer interrupção das atividades por tempo prolongado.

Na primeira etapa da intervenção foi prevista a reformulação de cerca de $135 \mathrm{~m}^{2}$, cujo escopo de serviços contemplava a criação de sala segura, três novas salas para entrevistas, além da reformulação geral do layout do espaço destinado à coordenação e equipe da coordenadoria de Gestão de Pessoas.

A segunda etapa prevista refere-se à reformulação de aproximadamente $90 \mathrm{~m}^{2}$, contemplando serviços necessários à redistribuição de layout físico da diretoria geral e vice-diretoria do Departamento, bem como recepção e arquivo. Foram propostas ainda intervenções na cozinha e refeitório dos servidores, com a criação de depósito para armazenamento de materiais.

A terceira e última etapa contempla a alteração de layout de setores administrativos, tais como de concursos e admissões e da secretaria geral, além da adequação de duas salas de aula e da coordenadoria de educação e desenvolvimento, em um total de aproximadamente $300 \mathrm{~m}^{2}$. No cômputo geral a reforma perfaz um total de cerca de 525 $\mathrm{m}^{2}$ de área de intervenção, compreendendo as três referidas etapas. De modo geral, foram necessárias demolições em alvenaria para abertura de portas, remoção de divisórias, instalação de paredes em drywall, fechamentos em vidro temperado, instalações de forro em gesso e de bancadas em granito, pintura geral e adequação das instalações elétricas e de lógica.

A primeira etapa já foi concluída diretamente pela equipe da Divisão de Reformas, que providenciou as compras de materiais e serviços pertinentes, antes mesmo da finalização do orçamento executivo. Do mesmo modo, a segunda etapa foi executada parcialmente por equipe própria da Manutenção, que providenciou a aquisição de materiais e serviços necessários à reforma do espaço destinado à diretoria e vicediretoria do Departamento (trecho 1 da reforma). Os serviços da terceira etapa não possuem previsão para início, até o momento.

A fase de pré-projetação foi iniciada a partir da solicitação do cliente, mais precisamente do Pró-Reitor de Recursos Humanos, uma vez que o Departamento de Recursos Humanos encontra-se vinculado àquela Pró-Reitoria. A solicitação foi formalizada através de ofício encaminhado ao Pró-Reitor de Planejamento que, em seguida, repassou o pedido ao Departamento de Projetos para análise.

Uma vez definida a equipe de projetistas que trabalhará no processo de desenvolvimento do projeto, sob a coordenação de um arquiteto da Instituição, iniciamse as discussões preliminares para posterior definição do programa de necessidades. 
Inicialmente são efetuadas buscas nos arquivos de desenhos da edificação existente de modo a subsidiar o estudo preliminar. Nesta fase é realizado um diagnóstico simplificado da edificação, mediante visitas ao local para averiguações, levantamentos e registro fotográfico.

O arquiteto coordenador do projeto e, no caso, autor do projeto, promove reuniões com o usuário para delinear o briefing e repassar as informações e condicionantes de projeto à equipe de projetistas para desenvolvimento do mesmo. Uma vez definido o programa de necessidades, o mesmo é submetido à aprovação e, sendo aprovado, dá-se o início ao desenvolvimento do estudo preliminar.

Se necessário, são realizadas demais visitas técnicas in loco para levantamentos e averiguações complementares. Um layout parcial é submetido à aprovação da coordenação geral do Departamento de Projetos e, em seguida, à direção do Departamento solicitante. Concomitantemente, o arquiteto coordenador, de posse do estudo preliminar aprovado, passa a desenvolver o anteprojeto e contatos iniciais com profissionais das demais especialidades para as discussões preliminares.

No caso, não foi realizada estimativa de custos preliminares para assegurar a viabilidade econômica da proposta. Tal procedimento possibilitaria análise técnica para um melhor direcionamento e integração das demais disciplinas envolvidas, com a participação da equipe de engenharia da Instituição. A análise técnica foi realizada de forma intuitiva pelo arquiteto coordenador, que promove a integração dos demais envolvidos, através do envolvimento da equipe de engenharia da Instituição.

Uma vez aprovado o projeto básico, iniciaram-se os projetos complementares e finalização do projeto executivo. Porém, antes da finalização, a compatibilização dos projetos das diversas disciplinas foi realizada pelo arquiteto coordenador e autor do projeto.

A compatibilização dos projetos foi realizada mediante sobreposição de plantas e cortes das diversas disciplinas envolvidas e outras verificações pertinentes. Outras atividades também foram realizadas pela coordenação, tais como controle de cronogramas de execução, encaminhamentos de documentos, validações necessárias e solução de conflitos.

Diante das conferências definitivas e validações necessárias, o projeto executivo foi concluído, em suas diversas etapas, sendo necessária a realização em seguida do caderno de especificações e do memorial descritivo, os quais permitiriam subsidiar o processo licitatório, no caso da terceirização dos serviços. Entretanto, neste caso, ambos os elementos não foram desenvolvidos.

A partir da segunda etapa, a arquiteta inicialmente escalada para o desenvolvimento do projeto foi substituída devido ao seu desligamento da Instituição. Entretanto, outro arquiteto do quadro efetivo assumiu a finalização das etapas subsequentes, tendo sido mantido o estagiário alocado inicialmente. Esta fase de transição entre projetistas acarretou atrasos no cronograma e perdas de informação ao longo do processo, uma vez que o programa definido pelo primeiro profissional precisava ser bem entendido para prosseguimento das etapas por parte do projetista substituto.

O tempo decorrido entre a concepção do projeto e a execução dos serviços por etapas tornou-se demasiadamente longo, gerando novas demandas não previstas inicialmente, levando a retrabalhos e atrasos no cronograma. Ao longo do processo de desenvolvimento das segundas e terceiras etapas, a quantidade de pessoas previstas no layout preliminar sofreu acréscimo de $50 \%$, sendo necessária nova readequação do 
projeto. Muitas vezes o usuário não tem consciência das implicações de revisões de projeto no que diz respeito ao desperdício de dinheiro público. A falta de conhecimento técnico e dificuldade de expressar desejos e necessidades também trazem transtornos quanto à delimitação do programa, gerando retrabalhos, desperdícios e atrasos no cronograma.

Após a aprovação do projeto básico por parte do usuário e estudo de viabilidades, inicia-se a segunda fase de projetação. No caso em estudo, o projeto executivo foi realizado pela equipe interna da Instituição, bem como os projetos complementares de instalações prediais.

Após as conferências definitivas e validações necessárias, o projeto executivo é concluído, passando-se à realização do caderno de especificações e do memorial descritivo, os quais subsidiarão a licitação para a contratação dos serviços. Ambos não foram elaborados no caso estudado.

A padronização própria para apresentação de projetos (layers, formatos, selos, codificação de pranchas, etc.) foi seguida pela arquitetura, tendo sido utilizada como referência também nos projetos complementares. Não há, entretanto, padronização geral de especificações. A inclusão de novos elementos construtivos na proposta tais como drywall e vidro temperado, deveu-se à racionalização de processos construtivos, objetivando rapidez de execução, funcionalidade e em atendimento a critérios de sustentabilidade.

Antes mesmo da entrega definitiva à produção, o pacote de projetos deve ser encaminhado ao setor de orçamentos para elaboração da planilha orçamentária. Nesta fase, podem ser detectadas incongruências que são repassadas ao Departamento de Projetos para revisão final, antes mesmo da licitação. Neste caso, os projetos da primeira etapa e parte da segunda etapa foram encaminhados para execução por equipe interna à Instituição. Ao receber o pacote de projetos, bem como o orçamento da obra, o engenheiro fiscal da obra assume a coordenação do processo. Este profissional elabora o pedido de compra e o termo de referência para contratação dos serviços e produtos sem, contudo, ter participado do desenvolvimento dos projetos, na maioria dos casos.

\section{DICUSSÃO E CONSIDERAÇÕES SOBRE O PROCESSO DE PROJETO}

As reformas são demandas constantes em Instituições universitárias públicas devido à dinâmica de readequação dos espaços físicos, que necessitam habitualmente ser adaptados às suas novas funções. Algumas vezes, na Instituição pública pesquisada, pequenas reformas são absorvidas pela equipe de manutenção. Porém, na grande maioria dos casos, há necessidade do devido processo licitatório para a contratação de empresas, tanto para a execução da obra, como para a elaboração dos projetos complementares. Desse modo, o controle da produção é parcialmente perdido.

Nesse contexto, são indispensáveis para o processo licitatório o projeto básico aprovado pela autoridade competente e o orçamento detalhado em planilhas que expressem a composição de todos os seus custos unitários.

A integração projeto/obra, uma das premissas do "projeto simultâneo" fica parcialmente prejudicada, uma vez que o art. $9^{\circ}$ da lei 8.666/1993 (BRASIL, 1993) implica em uma necessária segmentação e separação das atividades de concepção e execução. A Instituição universitária pública executa diversas obras de readequação predial, que apresentam muitos problemas de gerenciamento, controle dos processos e de execução, como no caso estudado nesse trabalho. 
Restrições de custo e prazo, bem como prioridades e necessidades da Administração Central, afetam as etapas do processo de projeto na Instituição universitária pública, sendo atropeladas ou interrompidas, prosseguindo sem uma adequada coordenação. Desse modo, muitas vezes são adotadas soluções pouco satisfatórias na compatibilização dos projetos na obra, podendo acarretar aumento do custo, comprometimento com a qualidade e atrasos no cronograma de obra. Os trabalhadores são organizados em cadeias de comando de cima para baixo, com poucas oportunidades de interagir com outras áreas funcionais.

Durante a execução dos serviços da primeira etapa, a Divisão de Reformas se deparou com algumas incompatibilidades de projeto. Verificou-se ainda ausência de projeto voltado à produção, bem como a não realização de adaptações do projeto de prevenção e combate a incêndio, uma vez que houve alteração do layout previsto no projeto existente, descaracterizando o ambiente em relação ao aprovado inicialmente junto ao Corpo de Bombeiros.

O forro de gesso monolítico especificado em projeto foi substituído durante a execução por forro de gesso removível, para que no futuro fosse possível a manutenção das instalações aparentes existentes sob o mesmo. O painel de madeira previsto na parede de uma das salas de entrevistas não possuía detalhamento executivo. Não foram contemplados detalhes de fixação, montagem e emendas dos painéis, o que levou à definição das soluções quando da especificação para a compra dos serviços. A moldura de granito para acabamento dos visores de atendimento externo foi especificada com largura incompatível com a espessura da parede existente. Tal fato atrasou o cronograma de execução da reforma, uma vez que foi necessária aquisição de nova moldura no mercado, inviabilizando assim o prosseguimento das etapas subsequentes, tais como fechamento em vidro temperado e pintura das alvenarias. $\mathrm{O}$ fato da estrutura ser pré-moldada demandou também solução no canteiro, no sentido de possibilitar a instalação de vidro temperado para fechamento de vão de esquadria, bem como a adaptação de molduras em granito, tendo em vista a deformação inerente à estrutura e a falta de detalhamento para fixação dos elementos.

Destacam-se as falhas na interação projeto-manutenção no planejamento de execução das etapas previstas, bem como inexistência de projeto voltado à produção. Embora a intenção, desde o início, de que os serviços fossem executados por equipe própria da Instituição, não houve interação devida entre as equipes envolvidas (projetomanutenção), levando à necessidade de definições por parte da fiscalização ao longo da execução da obra.

Deve-se salientar que uma das salas de entrevistas, concluída na primeira etapa, não está sendo utilizada atualmente para a finalidade proposta. Em visita recente ao local, verificou-se que o espaço vem sendo utilizado como depósito provisório. Tal fato se deve à proximidade da sala com o espaço atualmente destinado aos serviços gerais, bem como com a cantina de uso geral daquela Unidade, trazendo transtornos para 0 desenvolvimento das atividades corriqueiras devido ao barulho e odores decorrentes da preparação de refeições. Isso demonstra incompatibilidade entre a solução projetual e a real necessidade do usuário.

Verificou-se, ainda, que o longo espaço decorrido entre a concepção e a execução dos serviços possibilitou grande interferência de usuários no sentido de antecipar etapas, além de necessidade de adaptações do projeto, para atendimento às expectativas dos mesmos. Tal situação poderá se traduzir em incompatibilidades entre o projeto concebido e o produto final. 
As dificuldades e inconsistências observadas no processo de projeto da Instituição pesquisada levam à necessidade de revisão no fluxo do mesmo.

\section{DIRETRIZES PARA MELHORIA DO PROCESSO DE PROJETO}

O processo de projeto adotado na instituição pesquisada é realizado de certa forma integrado, embora não sejam adotados modelos teóricos consagrados. No entanto, há que se implementar melhorias neste processo, visando a redução de erros, aumento da produtividade e diminuição de prazos.

Em primeiro lugar, propõe-se a definição das macrofases do processo de projeto e as principais atividades em cada etapa. Os principais responsáveis devem ser definidos, incluindo os elementos de controle e os pré-requisitos aplicáveis. As macrofases necessitam ser bem delimitadas devido às validações e investimentos necessários, bem como em função do processo licitatório.

Assim, na macrofase de pré-projetação, deve-se definir com propriedade o diagnóstico e a proposta técnica que viabilize a melhor solução. Propõe-se uma vistoria conjunta da equipe técnica envolvida no processo, juntamente com os demais técnicos da Instituição nas diversas especialidades, objetivando uma maior integração das demandas dos usuários e das condicionantes de projeto.

O diagnóstico deverá ser documentado e apresentar os principais aspectos as serem contemplados, tais como legislação e normas técnicas, questões de sustentabilidade e acessibilidade, conforto térmico e acústico, orientação da edificação, exigências funcionais, etc. O levantamento fotográfico deverá fazer parte do mesmo, bem como os demais documentos e anotações julgadas pertinentes. O diagnóstico fornecerá parâmetros para elaboração do projeto preliminar.

Em seguida, estudos preliminares deverão ser realizados com consultoria das demais especialidades, para que a proposta técnica seja posteriormente submetida à aprovação do usuário. Uma vez aprovada a melhor solução pelo usuário, deve-se elaborar uma estimativa de custos que possibilite a avaliação do investimento, no intuito de se minimizar retrabalhos para adequação da proposta aos recursos financeiros disponíveis.

Na macrofase de projetação, as definições de contratação serão a base para todo o processo de execução dos projetos, quando necessários. Destaca-se a importância dos editais para contratação de projeto de edificações públicas, os quais devem contemplar diretrizes de forma dinâmica, integrando projetistas, construtores e sistemas construtivos, coordenados de maneira a atingir objetivos qualitativos que atendam ao interesse público.

No caso em estudo, tanto o projeto arquitetônico, como os projetos das demais especialidades, foram elaborados por técnicos da própria Instituição. Desta feita, o modelo proposto reforça a necessidade de elaboração de processo de projeto simultâneo, com vistas à total integração das diversas disciplinas envolvidas, contemplando atividades de compatibilização, no intuito de garantir um projeto de qualidade. Neste sentido, o escopo de cada disciplina deve ser bem definido, além das atividades pertinentes às mesmas e também as atividades comuns a todas elas.

Com base no diagnóstico preliminar, devem ser consideradas a legislação e normas técnicas vigentes, bem como requisitos de projetos, questões de acessibilidade, sustentabilidade, etc. A integração do processo, dessa forma, pode ser garantida, facilitando o gerenciamento e acompanhamento. 
O coordenador do projeto tem grande importância no planejamento do mesmo, devendo promover reuniões internas para garantir a perfeita integração dos escopos e cronogramas de trabalho.

Com o estudo preliminar concluído, é necessária uma análise inicial para compatibilização da solução proposta. Deve-se verificar se todas as incongruências e sugestões levantadas no diagnóstico foram contempladas no projeto. O procedimento de check list deve ser utilizado quando da finalização do projeto executivo.

A partir dos anteprojetos disponibilizados, deverá ser realizada reunião de compatibilização entre os projetistas e demais técnicos da Instituição envolvidos no processo. O coordenador deverá registrar as interfaces e soluções propostas para posterior detalhamento no projeto executivo.

Em seguida, as diversas especialidades elaboram o projeto básico para as aprovações nos órgãos competentes, quando necessário. Inicia-se, então, o detalhamento do projeto executivo, com as respectivas especificações.

Caso sejam necessárias alterações de projeto, o coordenador deverá repassá-las ao restante da equipe. As soluções, porém, devem ser discutidas e solucionadas entre os envolvidos, de forma descentralizada.

Na macrofase de pós-projetação, para uma melhor integração projeto/obra sugere-se que haja, antes mesmo do início da implantação da obra, uma apresentação geral do projeto à equipe de execução. Muitas vezes, o executor não participou da elaboração do projeto, tendo-se baseado apenas no orçamento da Instituição e documentos de licitação disponibilizados.

As alterações de projeto deverão ser registradas, bem como suas causas e o solicitante, favorecendo assim a retroalimentação para novos projetos. Da mesma maneira, a elaboração do projeto as built é imprescindível, devendo seus arquivos serem reorganizados em rede e disponibilizados para consultas.

Por fim, outro procedimento a ser implantado é a avaliação pós-ocupação (APO). A análise da qualidade do desempenho do ambiente construído é conduzida pela APO e os seus resultados constituem a base para organizar as informações disponíveis para o planejamento das alterações necessárias à adequação do espaço, segundo as funções requeridas pelo usuário.

Frequentemente atribui-se ao processo de projeto a estruturação dos resultados da APO para determinar os novos requisitos funcionais, tanto em reestruturação do espaço existente como na construção de um novo edifício. Porém, o ciclo do processo de construção pressupõe que as necessidades do cliente e do usuário sejam analisadas e estruturadas antes que a etapa de projeto tenha início (ROMERO e ORSTEIN, 2003).

\section{CONSIDERAÇÕES FINAIS}

No intuito de se otimizar o processo de projeto em Instituição universitária pública é indispensável a implementação de ferramentas gerenciais de coordenação de projeto, objetivando-se produzir projetos de qualidade que atendam à expectativa dos usuários.

Ficou evidenciada a importância do levantamento de dados, diagnóstico e diretrizes técnicas, considerados como "programa de necessidades", para evitar incompatibilidades com os requisitos do cliente e problemas na interface projeto/obra. 
A participação do cliente também é importante, principalmente quando se trata de readequações de prédios públicos ocupados, onde o funcionamento deve ser mantido durante o tempo de execução da obra. Foram identificadas deficiências quanto à elaboração de projetos voltados à produção e ausência de avaliação pós-ocupação.

Modelos e diretrizes voltados à coordenação e organização das atividades de projeto devem ser adotados de forma simplificada e flexível, no intuito de se adaptarem às especificidades da Instituição universitária pública, quer sejam em relação às burocracias internas, quanto à disponibilidade de recursos, escopos e prazos contratuais.

\section{REFERENCIAS}

ANDERY, P.; CAMPOS, C.; ARANTES, E. Desenvolvimento de um termo de referência para o gerenciamento de projetos integrados em uma instituição pública. Revista Gestão \& Tecnologia de Projetos, vol. 7, nº.1, São Carlos, 2012.

BRASIL. Lei n.o 8.666, de 21 de junho de 1993. Regulamenta o art. 37, inciso XXI, da Constituição Federal, institui normas para licitações e contratos da Administração Pública e dá outras providências. Disponível em:<http://www.planalto.gov.br/ccivil_03/leis/l8666cons.htm>. Acesso em: 07 de maio de 2014.

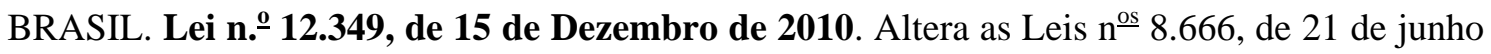
de 1993, 8.958, de 20 de dezembro de 1994, e 10.973, de 2 de dezembro de 2004; e revoga o § $1^{\underline{0}}$ do art. $2^{\underline{0}}$ da Lei $\mathrm{n}^{\mathrm{o}}$ 11.273, de 6 de fevereiro de 2006. Disponível em: <http://www.planalto.gov.br/ccivil_03/_Ato2007-2010/2010/Lei/L12349.htm>. Acesso em: 07 de maio de 2014.

ESTEVES, J.C. Planejamento e gestão do ambiente construído em universidades públicas. 2012. Dissertação apresentada ao Programa de Pós-Graduação em Engenharia Urbana Universidade de São Carlos, São Paulo.

FABRICIO, M.M. Projeto simultâneo na construção de edifícios. 2002. Tese de Doutorado em Engenharia - Escola Politécnica, Universidade de São Paulo, São Paulo.

INSTITUTO BRASILEIRO DE AUDITORIA DE OBRAS PÚBLICAS (IBRAOP). OT IBR 001/2006 - Orientações técnicas que dispõem sobre o projeto básico. Disponível em: $<$ http://www.ibraop.org.br>. Acesso em: 07 de maio de 2014.

KAGIOGLOU, M. et al. Process Management for Concurrent Life Cycle Design and Construction. In: ANUMBA, C, KAMARA, J. e CUTTING-DECELLE, F. (Eds.) Concurrent engineering construction projects. London: Taylor and Francis Editores, 2007, p. 98-117.

MARTINS, R.M.P. Análise do processo de projeto de reformas de edificações de universidade pública. 2014. Dissertação de Mestrado apresentada ao Programa de PósGraduação em Construção Civil - Universidade Federal de Minas Gerais, Belo Horizonte.

MOTA, V.; SALGADO, M.S. Gestão de Projeto em Instituição Pública: Estudo de Caso na Universidade Federal Fluminense. In: Simpósio Brasileiro de Gestão e Economia da Construção, SIBRAGEC 2013. Anais... São Carlos, Associação Nacional de Tecnologia do Ambiente Construído, 2013, 10 p.

ROMANO, F.V. Modelo de referência para o gerenciamento do processo de projeto integrado de edificações. 2003. Tese de Doutorado em Engenharia de Produção apresentada ao Programa de Pós-Graduação em Engenharia de Produção - Universidade Federal de Santa Catarina, Florianópolis.

ROMERO, M.; ORSTEIN, S. Avaliação pós-ocupação: métodos de técnicas aplicados à habitação social. Editado pela Antac. Porto Alegre, 2003.

TZORTZOPOLOUS, P.; COOPER, R. Design Management from a Contractor's Perspective: The Need for Clarity. Architectural Engineering and Design Management, vol. 3, nº 7, 2007. 